\title{
Investigation in Remediation of Wind Turbine Generator (WTG) Foundations with Epoxy Resin
}

\author{
Kay $A$. Bode \\ Vestas Deutschland GmbH, WTG Engineering \& Support, Kapstadtring 7, 22297 Hamburg, Germany
}

\begin{abstract}
This article shows the principle requirements for remediation of WTG foundations and the advantages and disadvantages of different injection materials like cement lime, epoxy resin and PUR resin. Mostly there are reservations against epoxy resin mainly because of assuming wet cracks in foundations. Regarding state of the art epoxy resins are not usable at wet surfaces or for cracks with liquid water inside. It will be shown that nevertheless it can work and why it works. There were done some basic investigations in how to fill a crack/gap between two concrete slabs. The gap was filled with water or a suspension to simulate a wet crack surface. The spread of an Epoxy resin in the gap was investigated.
\end{abstract}

\section{Introduction}

Onshore foundations of wind turbine generators (WTG) are mostly built from reinforced concrete. And like everywhere in concrete construction cracks, cavities or other imperfections could lead to a danger for stability of the whole construction. There are several reasons for cracks in concrete of foundations or loose steel embedment before end of lifetime. Anyway, the most common solution for these problems is to inject any kind of material what seems to be useful, like "quick and dirty". Seldom there is done a suitable inspection followed by a professional remediation planning before start of remediation works. Therefore, the risk for use of a not suitable method or material is very high.

Responsibly customers do a remediation planning first. The principle method is clear - drilling of some holes in the foundation concrete and injection of a suitable material. But only a responsible remediation planner has the knowledge to decide where the holes should be drilled, how many of them, the right diameter and the most important fact - which material should be injected. Regarding the German "Richtlinie für Schutz und Instandsetzung von Stahlbetonbauwerken (RILI-SIB 2001)" only cement lime or cement suspension is usable for these kind of cracks because it could be assumed that foundation cracks are always wet. But there are some new pure Epoxy resins (not hybrid PUR resins!) available on the marked for which the developers promise that they will also work under wet conditions or in cracks with liquid water in. Such materials are interesting in the wind industry for remediation of wind turbine foundations. Therefore, some investigations have been performed by Vestas, EFG Beratende Ingenieure $\mathrm{GmbH}, \quad \mathrm{W}+\mathrm{S}$ Bau-Instandsetzung $\mathrm{GmbH}$ and
INGVESTA to find out how the resin spreads in cracks depending on the environmental conditions in the cracks.

\section{Reason for Investigations}

A common method to strengthen the durability of cracked reinforced concrete is to inject a suitable material to close the cracks. Amongst other things depending on the kind of the cracks, the main tasks of the cracked reinforced concrete part and not least the remaining lifetime of the concrete component the right choice of an injection material is very important.

Mostly the main reason for use of an Epoxy resin to remediate a WTG foundation is the price. In fact, the costs for a remediation with Epoxy resins are two to three times lower than with cementitious materials. It seems to be surprising because the price for the material is much higher per $\mathrm{kg}$ as the price for cement lime or suspension.

The big point for Epoxy resin is the time. A remediation of a WTG foundation with Epoxy resins needs more or less five days, with cementitious materials around 10 to 15 working days. The reason for that is easy to explain - the kind of needed drill holes is crucial for the needed time.

While for Epoxy resins only small hole diameters are necessary, for cementitious materials only bigger hole diameters can be used. The advantage for small hole diameters (lower than $18 \mathrm{~mm}$ ) is the possibility to use normal drillers. This kind of drillers are no danger for reinforcements because if the driller hits a rebar the drill will stopped without a chance of continue and the rebar is not damaged. Usually it is not allowed to drill some special rebars to avoid statically problems. Furthermore, for this kind of drillings much less equipment is necessary and the speed of drillings is much higher.

\footnotetext{
* Corresponding author: kabod@vestas.com
} 
For the use of cementitious materials core drillings are necessary. To avoid damages on the important main rebar area in the top of a WTG foundation first bigger holes $(>300 \mathrm{~mm})$ will be drilled down near the reinforcement area, followed by jack hammering to locate the rebars. Only then can the injection holes be drilled between the rebars. This procedure is ornate and needs much more time.

Additionally, the needed mixing and injection equipment is much more extensive for using cementitious materials.

There are some more advantages for Epoxy resin. But the decisive disadvantage is the assuming of wetness in the cracks because it is a foundation in the ground. And this fact disqualified usually Epoxy resins for this task.

A further unknown is the stability of Epoxy material during long term dynamic loads because of the much lower modulus of elasticity related to concrete. There are no data available to assess the stability in different layer thicknesses of Epoxy during load cycles of $10^{10}$ to $10^{12}$ what is usual in the wind industry.

Nevertheless, the main point for these investigations was the fact that in the field are a lot of Epoxy remediation done in the past, mostly without a special remediation planning. And many of them are working since several years without further problems. As a responsible and customer-oriented manufacturer Vestas cannot ignore this fact. But for a good remediation planning some facts are missing. After study of some available remediation documentations the biggest dissent was the mount of used injection materials.

Regarding the current standards Epoxy resins are suitable for cracks from $0.1 \mathrm{~mm}$, cement lime or suspension for cracks from $0.2 \mathrm{~mm}$ crack width. Therefore, it would be expectable to inject more resin than cement lime. But in reality the opposite is the fact. For a remediation with cement lime usually 400 to 1000 litres of material will be used, of it about 70 litres to fill the drilled holes. For an Epoxy resin remediation usually 80 to 140 litres of material will be used, including approximately 10 litres to fill the drilled holes. This large deviation in the used material could not be explained. There might be a leak in knowledge how an injection material is spread out in a gap or a crack, what has to be clarified.

Another reason for the investigations was the fact that a crack system in a WTG foundation never is an ideal crack system to fill up. Due to the dynamical loads of the turbine the cracks are always moving. Therefore, there will be a lot of concrete abrasion, mud from the overburden and water present in the gaps and cracks. Usually, before the injection will be done the drilled holes will be flushed with a lot of water and air to bring out all lose material from these cracks. It is clear, this will be realized much better as bigger the drilling holes are. But it is not possible to clean the hole crack system, independent how big the drilled holes are or how long the duration of flushing is. In fact, there will be some dust and water remain in the cracks.

Beside the question regarding the spread out of an injection material in a clean crack the question for the spread out in a crack filled with dust and/or water in was important to clarify. Because Epoxy resin was the "unknown" material, the investigations were carried out with Epoxy resin.

\section{Scope of investigations}

To answer the questions of no. 2 three tasks had to be solved.

The first point was to find a suitable sample form and its dimensions. Criteria were a sample what can be handled manually in a laboratory, but strong enough to survive a maximum injection pressure of 100 bar. The surface should be as big as possible to guarantee a good comparability to the reality. The choice fell on concrete slabs with a dimension of $50 \times 50 \times 8 \mathrm{~cm}^{3}$. The concrete was a C40/50 with a maximum grain size of $16 \mathrm{~mm}$. The surface which simulates the crack was rough due to sandblasting. Two of these slabs formed one sample. They were close connected in the lower part and had a distance of $4 \mathrm{~mm}$ in the upper part. It should look like a "V". In this way the gap simulated a "crack" from 0 to $4 \mathrm{~mm}$. Side and bottom were closed with an usual (red) Epoxy resin for crack damming. Each of these concrete samples were stored in a metal frame to guarantee a high form stability during the injection. In the middle of the lower right third and in the middle of the upper left third a $10 \mathrm{~mm}$ hole was drilled thru one of the concrete slabs. In these holes the injection packers were fixed. The upper gap was closed by gluing a wood panel on this side. In the middle of this panel also a hole with an injection packer was placed (Fig. 1 and 2). Five samples were produced to simulate different conditions in a crack.

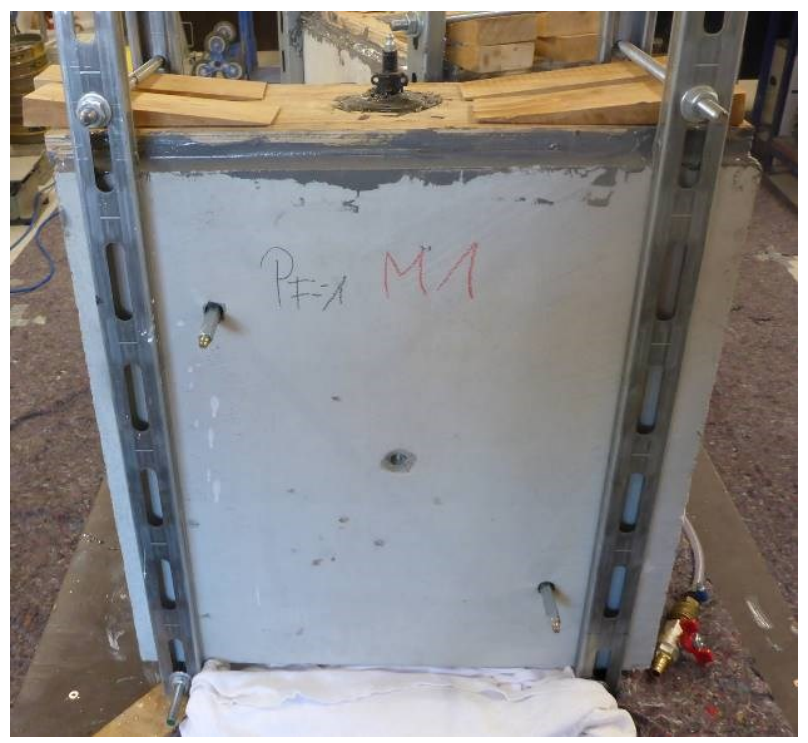

Fig. 1. Sample to simulate a crack injection

The second point was the reproducible simulation of concrete abrasions, mud and water in cracks. Therefore, a model substance was developed which contains parts of the most common findings in WTG foundation cracks. This suspension contained clay powder, Kaolin 
powder and water. With this suspension it was possible to create five different conditions in the sample gap:

1. PF-0: dry gap - the reference sample

2. PF-1: gap was filled with mud suspension two weeks before injection to get a sedimentation of particles in the crack, immediately before injection this sample was flushed with water and air thru the injection packer.

3. PF-2: gap was filled with water $30 \mathrm{~min}$ before injection, immediately before injection the water was blown out with air thru the injection packer.

4. PF-3: gap was filled with mud suspension $30 \mathrm{~min}$ before injection, immediately before injection this sample was flushed with water and air thru the injection packer.

5. PF-4: gap was filled with mud suspension $30 \mathrm{~min}$ before injection, the mud suspension was not blown out before injection

The third point was to create a test scenario which could show the success or the failure of an injection. Therefore, it was decided to cut each sample in five separate parts after hardening of the injection resin (Fig. 2). The in vertical direction outer right third and outer left third were to show the spread of the resin inside the gap. After cutting the filling of the gap could be assessed visually on the cutting line. After that the parts could be split in the two concrete slabs to assess the filling over the whole gap surface. The middle third was cut again horizontal in three parts. With this parts the adhesion should be tested in a shear test.

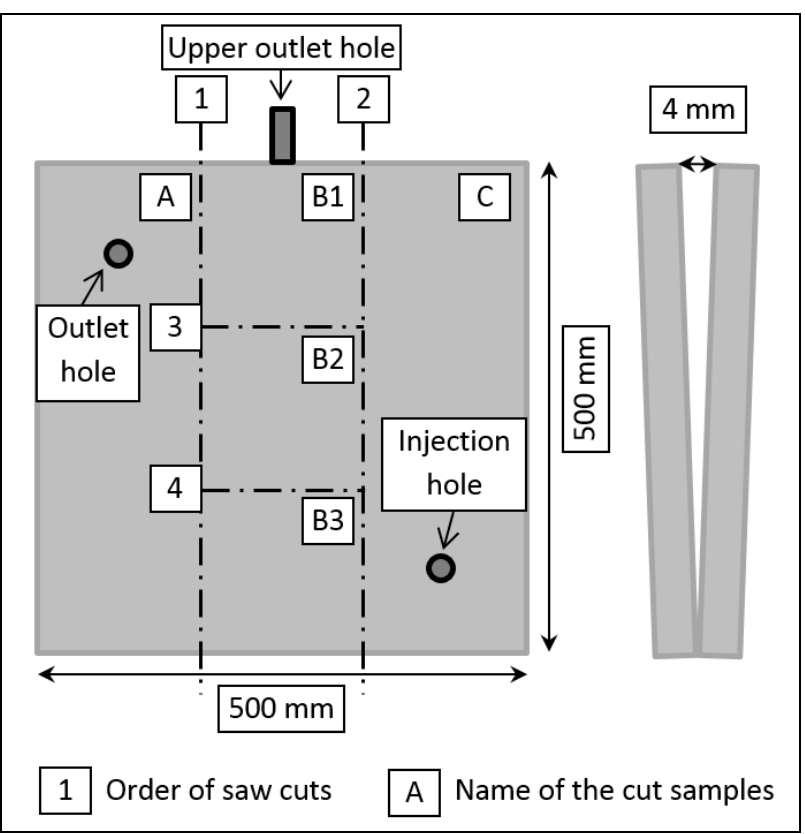

Fig. 2. Sketch of the samples including dimensions, position of injection packers and cutting lines and naming of the samples

Additionally, a sample of the pure resin was taken after the injection pump. From this, specimen were cut with the dimension $1 \times 1 \times 2,5 \mathrm{~cm}^{3}$ for a compressive strength test.

\section{Injection of the specimen}

In the laboratory of $\mathrm{W}+\mathrm{S}$ the specimen were injected with an typical Epoxy resin which is common for WTG foundations. This resin is "suitable for the injection under dry and wet conditions" and guarantees a "force fit adhesion" regarding the technical data sheet of the manufacturer. The Epoxy resin was mixed regarding the manufacturer specifications. After repotting and remixing the resin was filled in the reservoir of the injection equipment. A usual injection equipment was used (Fig. 3).

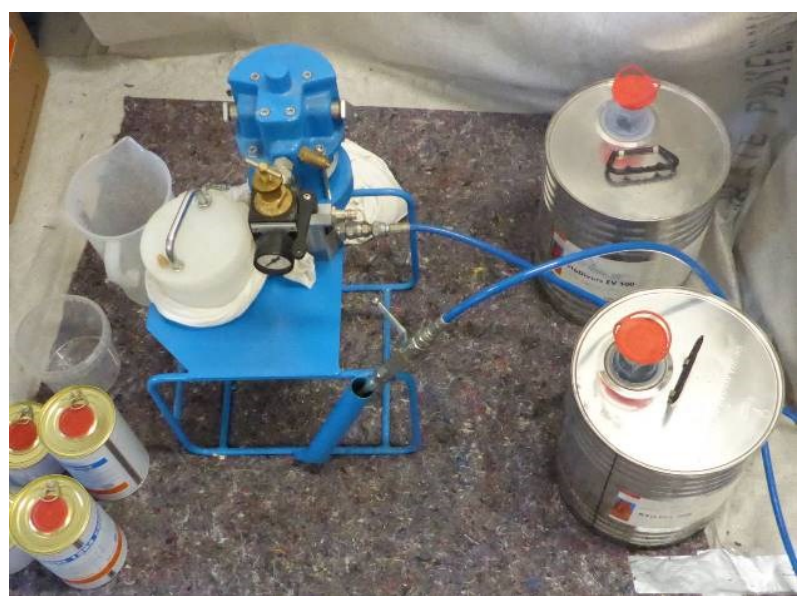

Fig. 3. Injection equipment

The injection equipment was connected to the packer in the lower right third of the specimen (Fig.4). The packers in the upper left third and on the top were open to let the resin comes out. When pure resin came out on the packer in the upper left third, this packer was closed. The injection procedure ended when pure resin came out on the packer on the top. Then all packers were closed.

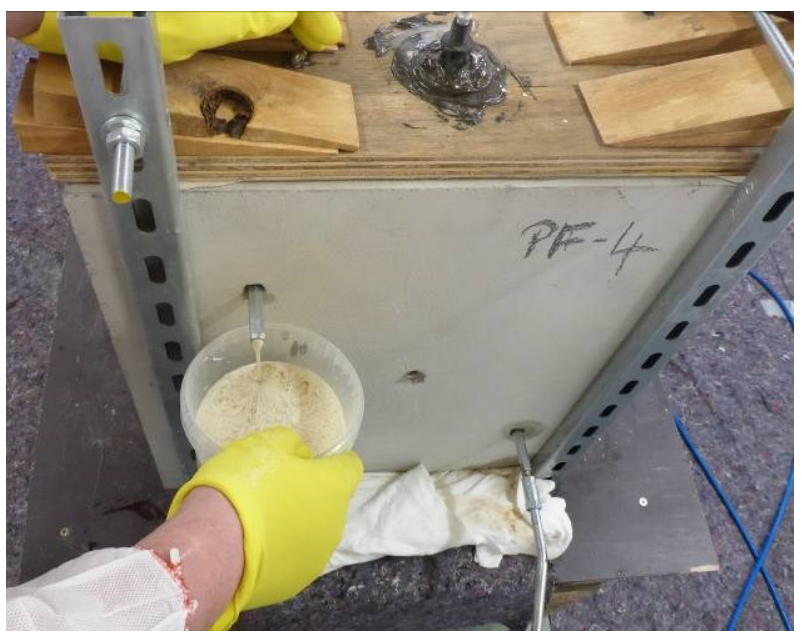

Fig. 4. Injection procedure

Especially interesting was the injection of specimen 4 where the resin was injected directly in the mud suspension filled gap (Fig. 4). There a lot of suspension came out of the outlet packer first. This was obviously a good sign of the workability of the resin because it was mentioned by the manufacturer that the resin push the water in front of him and will not mix. After finish of this injection the cans with the material from the outlet 
packer was left standing for around 2 hours. Than a separation of the mud suspension (in the top) and the resin (on the bottom) was visible (Fig. 5). At this point it could be assumed that the same process is running in the gap if there are rests of mud suspension in.

\begin{tabular}{|l|l|l|}
\hline $\begin{array}{l}\text { Pure resin } \\
\text { after the } \\
\text { pump to } \\
\text { prepare } \\
\text { specimen for } \\
\text { compressive } \\
\text { strength tests }\end{array}$ & $\begin{array}{l}\text { Second batch } \\
\text { of material } \\
\text { what comes } \\
\text { out of } \\
\text { specimen 4, } \\
\text { more or less } \\
\text { pure resin }\end{array}$ \\
\hline
\end{tabular}

Fig. 5. Separation of mud suspension and resin after 2 hours

After end of injection all specimen were stored some days under laboratory conditions.

\section{Testing of the specimen}

The specimen were tested on the Bauhaus University of Weimar at the F.A. Finger Institute for Building Materials Science. The first step was to cut the concrete samples (Fig. 6). During this process it was already clear that the adhesion between the both concrete slabs of each sample was not that much as expected. Most of the samples fall apart during cutting. On most of the specimen it was clear a shear test would not be possible. Only on the specimen where the crack was filled with mud suspension $30 \mathrm{~min}$ before injection and flushed immediately before injection the shear test was possible. But the results were also not that much.

Therefore, the evaluation of the injection could only be shown visually on the folded open vertical cut parts on the right and left of the specimen.

\subsection{Visual evaluation of the injection success}

\subsubsection{PF-0 - Reference sample (dry crack)}

On this sample a very good adhesion between Epoxy resin and concrete surface was expected. So it was all the more disappointing to see that there was also no adhesion measurable. Both concrete plates sticked together only due to a good form-fit. But it was already visible on the cutting line that the gap was not filled up in total. Especially the lower part is not filled at all. And it was possible to separate both concrete slabs without real force impact. The adhesion failed between concrete and Epoxy resin.



Fig. 6. Cuts on concrete sample PF3, the only with some adhesion

The view inside the gap shows the problem (Fig. 7). On the left side where the outlet hole is more than the half of the gap was not filled with resin. On the right side the gap is filled expect for a small part in the lower area. But the gap width in this area is also much more than 0.1 $\mathrm{mm}$ ! It seems that the resin found the shortest way from inlet to outlet without filling the area around this way.

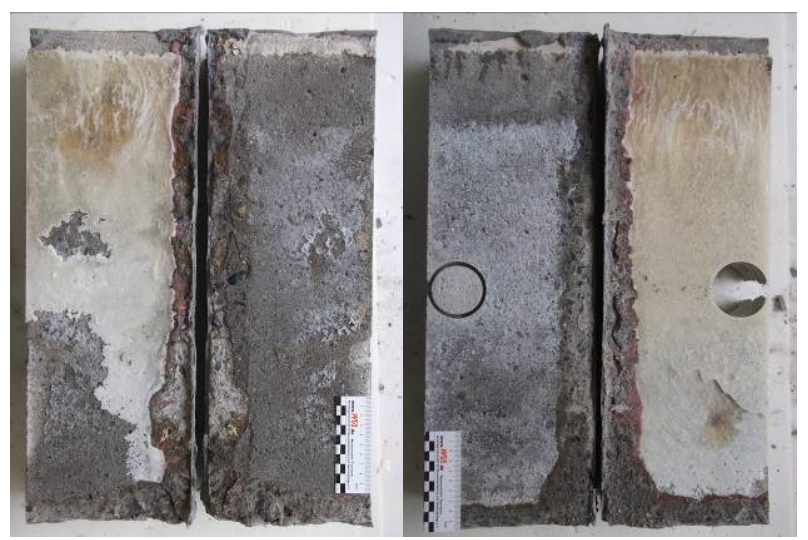

Fig. 7. PF-0: left: outlet hole in the top; right: inlet hole in the bottom

On the concrete part where the adhesion failed a white residue was visible (Fig. 8). It looks milky like in the contact zone between ordinary Epoxy resins and water, usually a sign of saponification. At this point this was not further investigated, but it is planned for future investigations.

\subsubsection{PF-1 - gap two weeks with mud suspension and flushed out}

The view inside looks similar to PF-0. The adhesion failed also between concrete and Epoxy resin (Fig. 9).

The first what is visible is the not successful flushing of the (sedimented) mud suspension. Below the inlet 
hole as well as below the outlet hole a lot of mud residues are visible. In this area no adhesion was possible because no resin could penetrate this area. It looks like on PF-0, the resin took the shortest way from inlet to outlet without filling the areas around.

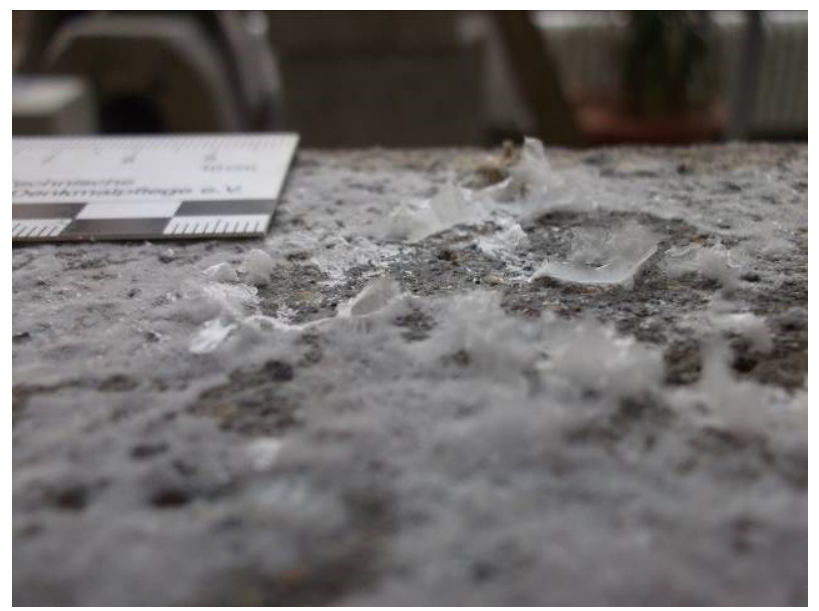

Fig. 8. PF-0: white residue on the concrete surface

The second conspicuity are the white residues on the concrete surface in the areas with resin. This looks also similar to PF-0 but indeed, here was water in the gap immediately before the injection. Unlike on PF-0 here is a chance for an explanation.



Fig. 9. PF-1: left: outlet hole in the top; right: inlet hole in the bottom

\subsubsection{PF-2 - gap 30 min with water and blown out}

The view inside looks also similar to PF-0 and the adhesion failed also between concrete and Epoxy resin (Fig. 10). The gap is not filled in total. But here is only the most resin missing area there where the gap is very small. As opposed to the other specimen here the gap below the outlet hole is also filled. Also, the white residues on the concrete surface are not as big and much as on PF-0 and PF-1. So it could be assumed that obviously the short penetration with water has an positive influence on the filling degree.

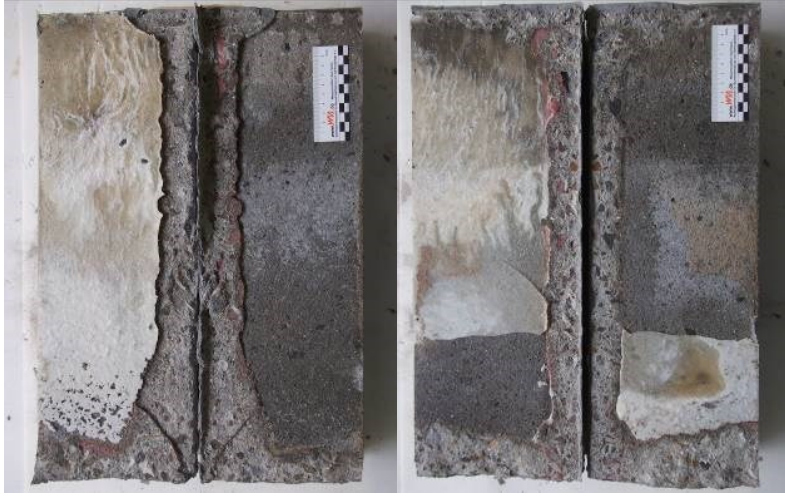

Fig. 10. PF-2: left: outlet hole in the top; right: inlet hole in the bottom

\subsubsection{PF-3 - gap 30 min with mud suspension and flushed out}

This was the only specimen with some measurable adhesion. A higher force was necessary to split the concrete slabs. A hammer and chisel must be used. The break was a combination of an adhesion failure between Epoxy resin and concrete and a cohesion failure in the concrete surface (Fig. 11 to 13). At the moment it is incomprehensible why there is this difference between PF-2 and PF-3 because both were filled with an liquid what was flushed and blown out. There are additional investigations necessary.

But regarding the filling of the gap it is the same as on all specimen. The gap is not filled in total. Especially below the outlet hole are bigger areas without resin. It seems again, the resin took only the shortest way.

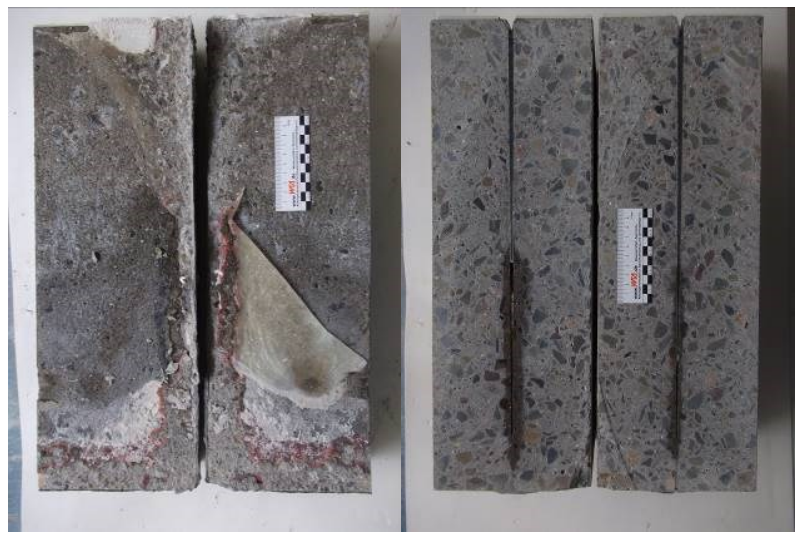

Fig. 11. PF-3: left: inlet hole in the bottom; right: cutting lines

\subsubsection{PF-4 - gap with mud, not blown out}

The view inside looks also similar to PF-0 and the adhesion failed also between concrete and Epoxy resin (Fig. 14). The gap is not filled in total because there was a lot of dry mud from the mud suspension in the gap. It seems the resin was not able to bring out all mud suspension or the resin does not reach a lot of areas in the gap. This is the ideal sample to show the way of an Epoxy resin in a mud filled crack. The area below the outlet hole is completely filled with dry mud. There was no possibility for resin to flow into this area. And the 
resin was not able to generate enough turbulences during the injection process to drive out the whole mud suspension



Fig. 12. PF-3: detail concrete surface with visible cohesion failure in the concrete

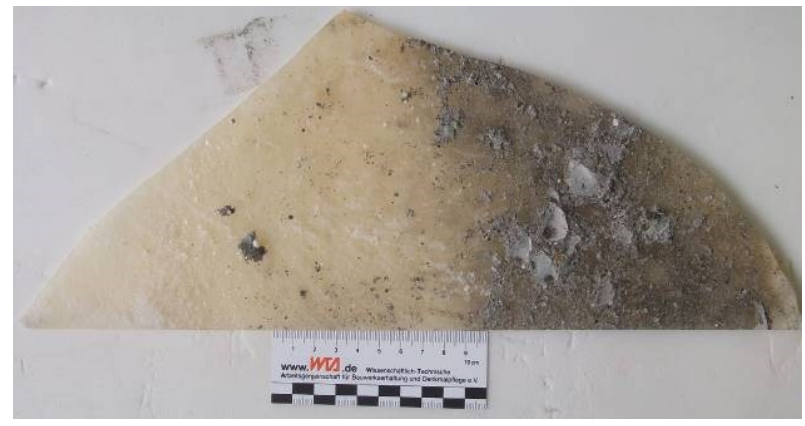

Fig. 13. PF-3: counterpart in Epoxy resin, cohesion failure in concrete visible



Fig. 14. PF-4: left: outlet hole in the top; right: inlet hole in the bottom

\subsection{Compressive strength of the Epoxy resin}

The compressive strength was tested on specimen with the dimension of $1 \times 1 \times 2,5 \mathrm{~cm}^{3}$. The tests were carried out also on the Bauhaus University of Weimar at the F.A. Finger Institute for Building Materials Science. The results (Table 1) show that obviously the curing conditions for the Epoxy resin were ideal. Regarding the data sheet the compressive strength should be around 60 $\mathrm{N} / \mathrm{mm}^{2}$. The Epoxy resin in the gap reached more than
$90 \mathrm{~N} / \mathrm{mm}^{2}$ in average. This is comparable to a high strength concrete. It means this resin is able to transfer much more loads than the usual foundation concrete.

Table 1. Compressive strength of the Epoxy resin

\begin{tabular}{|c|c|c|}
\hline $\begin{array}{c}\text { Sample } \\
\text { no. }\end{array}$ & $\begin{array}{c}\text { Breaking force } \\
{[\mathrm{N}]}\end{array}$ & $\begin{array}{c}\text { Compressive strength } \\
{\left[\mathrm{N} / \mathrm{mm}^{2}\right]} \\
\end{array}$ \\
\hline 1 & 15891,5 & 79,5 \\
\hline 2 & 16590,6 & 83,0 \\
\hline 3 & 19807,6 & 99,0 \\
\hline 4 & 17446,8 & 87,2 \\
\hline 5 & 19587,7 & 97,9 \\
\hline 6 & 19908,2 & 99,5 \\
\hline \multicolumn{2}{|c|}{ Average $\left[\mathrm{N} / \mathrm{mm}^{2}\right]$} & 91,0 \\
\hline \multicolumn{2}{|c|}{ Standard deviation $\left[\mathrm{N} / \mathrm{mm}^{2}\right]$} & 8,1 \\
\hline \multicolumn{2}{|c|}{ Variation coefficient [\%] } & 8,9 \\
\hline
\end{tabular}

\section{Conclusions}

In the article investigations in the spread of an injected Epoxy resin in a small crack/gap which was filled with different substances were described. It should improve the understanding for this procedure to assess why an Epoxy injection could be successful also under wet conditions.

The results were surprising because no one of all test scenarios delivered a perfect result. Especially the expected good bond under dry conditions could not be realized. Therefore, from this first model tests the following conclusions can be drawn:

- Resins will not penetrate very thin gaps, e.g. with a crack width of $0.1 \mathrm{~mm}$, if enough bigger crack areas are available.

- Independent of the highness of the injection pressure resins will find the shortest way to the next outlet. If this "street" is formed, the areas around are not affected anymore.

- After these investigations it must be assumed that the requirement of the most standards regarding a filling degree of $80 \%$ of all cracks cannot be guaranteed for foundations because of assumed mud in the cracks.

- It seems a good adhesive bond between resin and concrete is not depending alone by dryness of the crack or concrete. Also under wet conditions a higher bond could be possible and the resin can cure sufficiently in the crack.

- The high strength of the resin could be one point for a successful Epoxy resin injection. The aim of a remediation of a WTG foundation is always to stabilize a moving of an embedment and to guarantee a transfer of compressive forces in cracks and gaps. If there is a good form fit between resin and concrete all compressive forces can be transferred. And due to the high strength of the resin only miner points of connection are necessary to transfer all loads.

These investigations were the first step to get a deeper knowledge about the use of Epoxy resins in wet concrete cracks to remediate a WTG foundation. Further 
tests are necessary to plan save remediation until end of the lifetime of a wind turbine.

Great thanks for the support of planning these investigations, preparing and injection of the specimen at $\mathrm{W}+\mathrm{S}$ laboratory applies to Mr. Rubba and Mr. Wagenknecht from W+S BauInstandsetzung $\mathrm{GmbH}$, Fuldabrück/D, Mr. Geselle and Mrs. Kienzler from EFG Beratende Ingenieure $\mathrm{GmbH}$, Fuldabrück/D and Mr. Dee from INGVESTA, Kaufungen/D.

Also, great thanks to Mr. Flohr from the Bauhaus University of Weimar for supporting the tests of the specimen. 